Article

\title{
Design and Evaluation of Dissolving Microneedles for Enhanced Dermal Delivery of Propranolol Hydrochloride
}

\author{
Jingjing He ${ }^{1}$, Zichen Zhang ${ }^{1}$, Xianzi Zheng ${ }^{1}$, $\mathrm{Lu} \mathrm{Li}^{1}{ }^{1}$, Jianping $\mathrm{Qi}^{1}{ }^{1}$, Wei $\mathrm{Wu}^{1,2}$ (I) and $\mathrm{Yi} \mathrm{Lu}{ }^{1, *(\mathbb{D})}$ \\ 1 Key Laboratory of Smart Drug Delivery of MOE, School of Pharmacy, Fudan University, \\ Shanghai 201203, China; 18211030016@fudan.edu.cn (J.H.); 19211030017@fudan.edu.cn (Z.Z.); \\ 19211030024@fudan.edu.cn (X.Z.); 20211030026@fudan.edu.cn (L.L.); qijianping@fudan.edu.cn (J.Q.); \\ wuwei@shmu.edu.cn (W.W.) \\ 2 Center for Medical Research and Innovation, Shanghai Pudong Hospital, \\ Fudan University Pudong Medical Center, Shanghai 201399, China \\ * Correspondence: fd_luyi@fudan.edu.cn
}

Citation: He, J.; Zhang, Z.; Zheng, X.; Li, L.; Qi, J.; Wu, W.; Lu, Y. Design and Evaluation of Dissolving Microneedles for Enhanced Dermal Delivery of Propranolol Hydrochloride. Pharmaceutics 2021, 13, 579. https://doi.org/10.3390/ pharmaceutics13040579

Academic Editors:

Mireia Mallandrich,

Francisco Fernández-Campos and Patrick J. Sinko

Received: 8 March 2021

Accepted: 16 April 2021

Published: 19 April 2021

Publisher's Note: MDPI stays neutral with regard to jurisdictional claims in published maps and institutional affiliations.

Copyright: (c) 2021 by the authors. Licensee MDPI, Basel, Switzerland. This article is an open access article distributed under the terms and conditions of the Creative Commons Attribution (CC BY) license (https:// creativecommons.org/licenses/by/ $4.0 /)$.

\begin{abstract}
Oral propranolol hydrochloride has been the first-line treatment for infantile hemangioma (IH), whereas systemic exposure to propranolol has the potential of causing serious adverse reactions. Dermal delivery of propranolol is preferable due to high local drug concentration and fewer adverse effects. However, propranolol hydrochloride (BCS class I) is highly hydrophilic and has difficulty in penetrating the stratum corneum (SC) barrier. Dissolving microneedles (MNs) are an efficient tool for overcoming the barrier of the SC and enhancing dermal drug delivery. In this study, propranolol hydrochloride-loaded dissolving MNs were fabricated by using hyaluronic acid and polyvinyl pyrrolidone as matrix materials. Controllable drug loading in needle tips was achieved by a two-step casting procedure. The needles were good in mechanical strength for penetrating the SC while presented excellent dissolving capability for releasing propranolol hydrochloride. In comparison with the solution counterpart, irrespective of being applied to intact skin or solid MNs-pretreated skin, dissolving MNs significantly increased the permeability and skin retention of propranolol. In conclusion, dissolving MNs could be a potential approach for enhancing dermal delivery of propranolol to treat IH.
\end{abstract}

Keywords: microneedles; propranolol hydrochloride; dermal delivery; hyaluronic acid; polyvinyl pyrrolidone; infantile hemangioma

\section{Introduction}

Dermal delivery is a preferable drug administration method for treating diseases localized within the skin due to its advantages of higher local drug concentration, lower systematic exposure, absence of hepatic first-pass metabolism, and better patient compliance [1]. However, the barrier function of the stratum corneum (SC) prevents the entry of the majority of therapeutics into the skin [2], particularly the hydrophilic ones [3,4]. A myriad of physical devices and approaches, such as microneedles (MNs) [5-7], iontophoresis [8-10], sonophoresis [11-13], magnetophoresis [14-16], electroporation [17-19], and photomechanical wave [20-22], have been developed to facilitate cutaneous penetration. Microneedles, an array of micron-sized needles, are the most effective because they enable breaking the barrier of the stratum corneum for delivery of therapeutics into the skin [23,24]. In addition, the needles are only $0.2-1.5 \mathrm{~mm}$ in length, producing minimal invasion and enabling self-administration like a patch $[25,26]$.

So far, four types of MNs have been created, i.e., solid, hollow, coated, and dissolving MNs [27]. The first three types are made from silicon or metals. The fracture of the needles may cause severe damage to the skin [28]. Dissolving MNs consist of water-soluble matrix materials such as polyvinyl pyrrolidone (PVP), hyaluronic acid (HA), maltose, dextran, albumin, and chondroitin sulfate, while drugs are dispersed or dissolved in the 
needles $[6,28,29]$. Following insertion into the skin, the needles dissolve upon imbibing water from the interstitial fluids and release the drug payloads. Therefore, drugs are directly delivered into the skin to exert therapeutic effects [30], while no sharp needles are left behind [31,32]. Moreover, the manufacture of dissolving MNs is comparatively easier than other types of MNs. Dissolving MNs have been developed to deliver a series of drugs, including small molecules and macromolecules, such as DNA and protein [33-35].

Propranolol hydrochloride is a nonselective $\beta$-adrenergic receptor blocker, initially introduced to treat arrhythmias [36]. In 2008, oral delivery of propranolol hydrochloride was found to be highly effective for the treatment of infantile hemangiomas (IH), a common tumor of blood vessels in skin that usually occurs in infancy [37]; it then became the first-line medication. However, systemic exposure to propranolol hydrochloride may induce changes in sleep patterns, acrocyanosis, and gastrointestinal symptoms, and even serious adverse reactions including symptomatic hypotension, hypoglycemia, and bradycardia $[38,39]$. In contrast, dermal application of propranolol hydrochloride generates less untoward effects compared with the oral route for treating superficial hemangiomas, benefiting from high local drug concentration and less systemic exposure [40-42]. However, propranolol hydrochloride (BCS class I) has low transdermal transport efficiency due to its high hydrophilicity [43]. Many attempts have been made for developing preparations of propranolol aimed at enhancing the dermal permeation of propranolol [44-46]. Dissolving MNs could pierce the SC and directly deliver the drug into skin with little or no pain, which is an effective tool for enhanced dermal drug delivery [47,48]. Nevertheless, traditional dissolving MNs carry drugs in whole needles, inevitably leading to a waste of medicine due to the needles not being fully inserted into skin [49,50]. Hence, dissolving MNs were designed in this study to enhance skin delivery and retention of propranolol hydrochloride. Meanwhile, the drug was concentrated in the tip of the needles via a two-step casting procedure to avoid drug waste during preparation and application. Having the therapeutics confined in the tip of the needles can minimize drug loss, control penetration depth, and ensure drug loading [51].

In this study, a two-step casting procedure was proposed for the fabrication of dissolving microneedles for loading propranolol hydrochloride in needle tips. HA and PVP-K90 were utilized as the matrix materials of the needles. The MNs were characterized for their mechanical properties, morphology, drug release profiles, and skin penetration. The puncture performance and skin recovery after MN treatment were also assessed. IVIS was used to evaluate the retention profile of the drug in the skin. Additionally, skin permeation and retention of propranolol hydrochloride were quantified.

\section{Materials and Methods}

\subsection{Materials}

Hyaluronic acid ( $\mathrm{HA}, \mathrm{Mw}=10 \mathrm{kDa}$ ) was provided by Furuida Biotechnology Co., Ltd. (Shandong, China). PVP-K90 was obtained from Shengpu New Materials Co., Ltd. (Shanghai, China). Propranolol hydrochloride was obtained from Yuancheng Technology Co., Ltd. (Hubei, China). Polydimethylsiloxane (PDMS) MNs mold was supplied by Prof. Wu, C.B. at College of Pharmacy, Jinan University. Rhodamine B and fluorescein isothiocyanate isomer I (FITC) were provided by Sigma-Aldrich Co. (Darmstadt, Germany). Sodium chloride $(\mathrm{NaCl})$, ammonium metaphosphate $\left(\mathrm{Na}_{2} \mathrm{HPO}_{4}\right)$, potassium dihydrogen phosphate $\left(\mathrm{KH}_{2} \mathrm{PO}_{4}\right)$, lauryl sodium sulfate, and chloral hydrate were obtained from Sinopharm Chemical Reagent Co., Ltd. (Shanghai, China). Deionized water was produced by a Milli-Q purification instrument (Millipore, MA, USA). All other reagents were of analytical grade. Full thickness Bama porcine skin was purchased from Kaikai Technology Trade Co., Ltd. (Shanghai, China). Male SD rats weighing $150 \pm 10 \mathrm{~g}$ were obtained from Shanghai SLAC Laboratory Animal Co., Ltd. (Shanghai, China). All animal experiments were implemented under the approval of Institutional Animal Care and Use Committee at School of Pharmacy, Fudan University. Rules outlined in the Declaration of Helsinki for all human and animal experimental investigations were complied with. 


\subsection{Preparation of Blank and Drug-Loaded Dissolving MNs}

Micromolding is the most common strategy for the fabrication of MNs [52-54]. The MNs were fabricated by a micromolding method using HA and PVP-K90 via a two-step casting procedure (Figure 1) [55]. Briefly, the tip solution was prepared by dissolving HA and PVP-K90 with a weight ratio of 1:1 in distilled water to a concentration of $30 \%$ $(w / w)$. The backing solution was prepared by PVP-K90 with the concentration of $30 \%(w / w)$. The tip solution of $200 \mu \mathrm{L}$ was poured into the PDMS mold, which was centrifuged at $4000 \mathrm{rpm}$ for $5 \mathrm{~min}$ to depress the solution into the PDMS mold cavities. After removing the excess solution, the PDMS mold was kept in the silica gel desiccator overnight to facilitate drying. Subsequently, $400 \mu \mathrm{L}$ backing solution was added into the PDMS mold and then centrifuged at $4000 \mathrm{rpm}$ for $10 \mathrm{~min}$. The molds were put in the desiccator and dried for $24 \mathrm{~h}$. Finally, the dissolving MNs were gently removed from the molds and preserved in the desiccator. In this experiment, PDMS molds could be reused in the MN production process to improve fabrication efficiency [56,57].

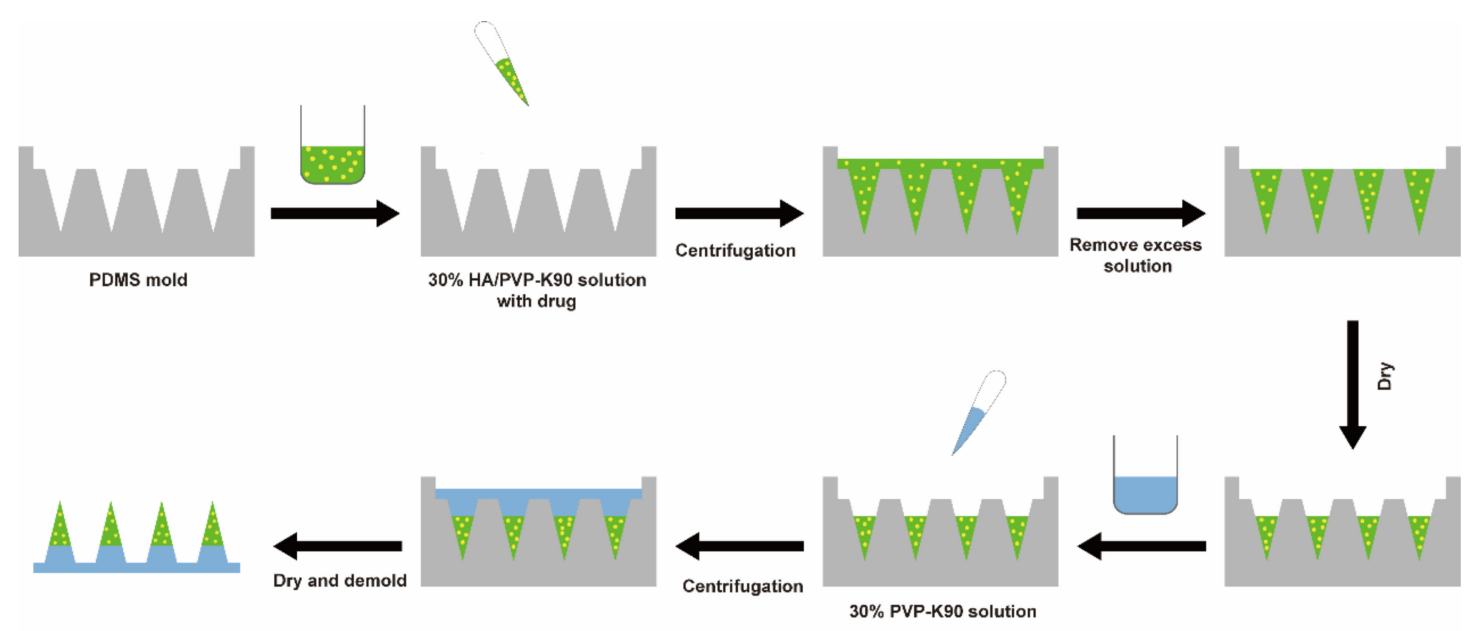

Figure 1. Schematics of the fabrication process of propranolol hydrochloride loaded MNs.

For the convenience of characterization and evaluation, methylene blue and FITC were used as model drugs to add in the tip matrix solution when needed and were then cast into the mold to fabricated MNs as described above.

To load propranolol hydrochloride in MNs, propranolol hydrochloride was added to the tip solution, and the final concentration of propranolol hydrochloride in the tip solution was controlled at 40, 50, 60, 70, and $80 \mathrm{mg} / \mathrm{mL}$, then cast into the mold as described above.

\subsection{Morphology of $M N s$}

The morphology of MNs was observed by field emission scanning electron microscope (JEOL Ltd., Tokyo, Japan), while the drug distribution of the MNs was observed by inverted fluorescence microscope (OLYMPUS Ltd., Tokyo, Japan) with the aid of methylene blue and FITC. The height, needles pitch, and width of MNs base were evaluated.

\subsection{Mechanical Property of MNs}

The mechanical property of the MNs was measured by a TA-XT2i Texture Analyzer (Stable Micro Systems, Haslemere, UK) in compression mode as in a previously reported method [47]. The test distance was set at $900 \mu \mathrm{m}$ with the trigger type at auto force. The pre- and post-test speed was $1 \mathrm{~mm} / \mathrm{s}$, while the test speed was $0.1 \mathrm{~mm} / \mathrm{s}$. The trigger force was set at $0.02 \mathrm{~N}$. The tips of the MNs were kept upward, which were pressed by an axial compression force via the texture analyzer. The force was then analyzed to obtain a force-displacement curve, and the failure force of MNs was recorded as the needles began to break. Finally, the morphology of the compressed MNs was observed by a microscope. 


\subsection{In Vitro Skin Insertion Tests}

To evaluate the penetrating ability of MNs, the isolated porcine skin was taken out from $-20{ }^{\circ} \mathrm{C}$ refrigerator and washed with $0.9 \mathrm{wt} \%$ normal saline solution before use, a process done to make sure the skin retained its elasticity and texture after defrosting. After the water on the skin surface was dried by filter paper, the porcine skin was placed in the PDMS block, and then the MNs were punctured into the skin for 5 min using thumb force. Next, the insertion region was recorded by a digital camera. The skin treated by MNs was also analyzed through frozen tissue sections technology. The frozen tissue was cut into $10 \mu \mathrm{m}$ thick slides using freezing microtome (Lecia, Wetzlar, German) and then placed on adhesion microscope slides. The tissue slide was stained by hematoxylin and eosin (H\&E) as well as being photographed under a microscope.

FITC was used as a model drug to further assess the drug permeation in skin. Following insertion into the porcine skin for $5 \mathrm{~min}$, the skin was analyzed by confocal laser scanning microscope (CLSM, Carl Zeiss, Jena, German) using Z-stack mode. Scanning of the xy-plane was operated at an interval of $10 \mu \mathrm{m}$ from the skin surface to inside via vertical direction. FITC was excited at $488 \mathrm{~nm}$ wavelength, with the emission wavelength being $525 \mathrm{~nm}$. The depth of scanning was set from the skin surface to the plane where fluorescence disappeared.

\subsection{In Vivo Dissolution of MNs after Insertion}

For evaluation of in vivo dissolution of the MNs after insertion, the hair on the abdomen of SD rats was shaved before the experiment and methylene blue was loaded in the MNs for the ease of observation. During the experiment, the SD rats were anesthetized by $5 \%$ chloral hydrate, then the MNs were applied on the abdominal skin. MNs were removed from skin at predetermined intervals of 5, 10, and $20 \mathrm{~min}$, respectively, which were observed by optical microscope to obtain the dissolved morphology of MNs.

\subsection{In Vivo Skin Recovery after MNs Insertion}

As a part of basic safety efforts, a preliminary skin recovery study was performed, in which methylene blue was loaded in the MNs in order to easily observe the skin irritation and recovery from MNs insertion. The hair on the abdomen of SD rats was depilated followed by the insertion of MNs into the abdominal skin, and MNs were then removed from the skin $5 \mathrm{~min}$ later. Photographs of the insertion area penetrated by MNs were taken by digital cinema after $0,1,2,3,6$, and $12 \mathrm{~h}$ until blue micropore on the skin became invisible.

\subsection{Drug Release from MNs}

The drug release profile was evaluated by Franz diffusion cell (Kaikai Technology Trade Co., Ltd., Shanghai, China), in which the tips of the MNs were immersed into $8 \mathrm{~mL}$ $0.9 \mathrm{wt} \%$ normal saline solution in the receiver compartment, which was stirred at $200 \mathrm{rpm}$ with the temperature set around $32 \pm 0.5^{\circ} \mathrm{C}$. Sample $(200 \mu \mathrm{L})$ was collected at $1,3,5,10$, $15,20,30$, and $60 \mathrm{~min}$ from the bottom of the receiver compartment, respectively, and equal volume of fresh $0.9 \mathrm{wt} \%$ normal saline solution was supplemented immediately. The samples were diluted properly for analysis via HPLC.

\subsection{In Vivo IVIS Image}

The IVIS spectrum live imaging system (Perkin Elmer, Waltham, MA, USA) was used to assess the skin retention of drugs. Prior to the experiment, SD rats were anesthetized by $5 \%$ chloral hydrate, and the abdominal hair was depilated. Dissolving MNs loaded with both rhodamine B $(20 \mu \mathrm{g})$ and propranolol hydrochloride $(1.5 \mathrm{mg})$ were fabricated as described above, which were applied to the abdominal skin in SD rats for $10 \mathrm{~min}$. For comparison, a rhodamine B solution $(0.1 \%, 20 \mu \mathrm{L})$ was subcutaneously injected in the abdomen of an SD rat. The SD rats were imaged by IVIS at $30 \mathrm{~min}, 1,2,4,6,8,10,12$, and 
$24 \mathrm{~h}$ after administration under Epi-Illumination mode with an excitation wavelength of $554 \mathrm{~nm}$ and emission wavelength of $580 \mathrm{~nm}$.

\subsection{Ex Vivo Skin Retention and Drug Permeation}

Ex vivo drug permeation was evaluated using Franz diffusion cell with a diffusion area of $1.77 \mathrm{~cm}^{2}$. Full thickness backing skin of Bama porcine was collected for this study. The dissolving MNs array with a surface area of $0.64 \mathrm{~cm}^{2}$ containing $1.5 \mathrm{mg}$ propranolol hydrochloride in the tip of the needles was inserted into the skin by thumb force, which was then fixed between the donor and acceptor compartment of the Franz diffusion cell. For comparison, a propranolol hydrochloride aqueous solution $(1.5 \mathrm{mg} / \mathrm{mL})$ was set as control, which applied $1 \mathrm{~mL}$ to either intact skin (solution-intact skin) or solid MNs to pretreated skin (solution-pretreated skin). The receiver fluid was $8 \mathrm{~mL} 0.9 \mathrm{wt} \%$ normal saline solution, which was stirred at $200 \mathrm{rpm}$. The temperature of the receiver fluid was controlled to get a skin surface temperature of $32 \pm 0.5^{\circ} \mathrm{C}$ at $1,2,4,6,9$, and $12 \mathrm{~h}$ post-administration; samples were withdrawn from the receiver compartment and equal volume of fresh receiver fluid was added in the meantime. The samples were analyzed via HPLC.

The skin retention was also evaluated using the same procedure, except that the porcine skins were collected at 1, 2, 4, 6, 9, and $12 \mathrm{~h}$ post-administration. The skin was washed with $0.9 \mathrm{wt} \%$ normal saline solution three times to remove any propranolol hydrochloride that remained on the surface. Then the skin was cut into small pieces. Propranolol hydrochloride in the skin was extracted with methanol under ultrasonic for $20 \mathrm{~min}$. The skin was then homogenized and centrifuged at 12,000 rpm for $30 \mathrm{~min}$. After that, the supernatant was collected and centrifuged again at $8000 \mathrm{rpm}$ for $30 \mathrm{~min}$. Finally, the supernatant was diluted for analysis via HPLC. Skin drug concentration was recorded as $\mu \mathrm{g} / \mathrm{cm}^{2}$.

\subsection{HPLC Methods and Drug Loading}

To quantify the propranolol hydrochloride content in MNs, the tip was first removed from the MNs patch and dissolved in $1 \mathrm{~mL}$ saline solution. The solution was vortexed for 5 $\mathrm{min}$, followed by centrifuging for $10 \mathrm{~min}$ at $4000 \mathrm{rpm}$. The supernatant was collected and diluted appropriately for analysis via Agilent 1100 HPLC system (Agilent, Santa Clara, CA, USA).

Propranolol hydrochloride was separated by Agilent ZORBAX Eclipse XDB-C18 column $(4.6 \mathrm{~mm} \times 250 \mathrm{~mm}, 5 \mu \mathrm{m}, \mathrm{CA}$, USA). The flow rate and the column temperature were set at $1 \mathrm{~mL} / \mathrm{min}$ and $35^{\circ} \mathrm{C}$, respectively. The mobile phase was composed of equal volume of acetonitrile and water, which contained $1.6 \mathrm{~g}$ lauryl sodium sulfate and $0.1 \mathrm{~g}$ $\mathrm{NH}_{4} \mathrm{H}_{2} \mathrm{PO}_{4}$ per $1000 \mathrm{~mL}$. The detection wavelength was $290 \mathrm{~nm}$ with $10 \mu \mathrm{L}$ injection volume. In the range of 1.563-50 $\mu \mathrm{g} / \mathrm{mL}$, a good linear relationship was found between the peak area (A) and the concentration $(\mathrm{C})$ of propranolol hydrochloride, with a typical calibration curve of $\mathrm{A}=11.575 \mathrm{C}-3.0378\left(R^{2}=1\right)$. The extraction recovery rate, accuracy, and precision were all in line with biological sample analysis requirements.

\subsection{Data Analysis}

All data are expressed as mean \pm standard deviation (SD), and all the experiments were repeated at least three times. Statistical analysis was conducted by SPSS (16.0) and one-way ANOVA was applied for groups comparison; a $p$ value $<0.05$ was considered statistically significant.

\section{Results and Discussion}

\subsection{Morphology of the MNs and Drug Distribution}

In this study, HA and PVP-K90 were used as matrix materials to produce MNs. HA is a natural linear polysaccharide with excellent water solubility, biocompatibility, biodegradability, and mechanical properties, which has been used extensively in the fabrication of MN [58-60]. However, dissolving MNs prepared only by HA have high 
fragility, whereas PVP-K90 is a polymer with good toughness and hardness [30,61,62]. Thus, PVP-K90 was used to adjust the mechanical strength and fragility of the MNs. Figure 2A shows the morphology of dissolving MNs. The needles present obelisks, being $1200 \mu \mathrm{m}$ in height with a side length of $300 \mu \mathrm{m}$ in the base. The shape proved to be better in penetration and higher in cutaneous delivery efficiency than pyramidal or circular ones [63]. The needles were arranged in a $12 \times 12$ array in a patch of $8 \mathrm{~mm} \times 8 \mathrm{~mm}$ with a center-tocenter interval of $600 \mu \mathrm{m}$. Furthermore, the two-step procedure of casting was adopted for loading drugs in the tips of the needles $[64,65]$. As shown in Figure 2B,C, methylene blue and FITC were primarily dispersed in the tips of the needles. This fabrication method could avoid drug waste during preparation and application. Furthermore, there was no need to insert full-length needles, which could reduce the stimulation of the MNs to the nerve and reduce pain.
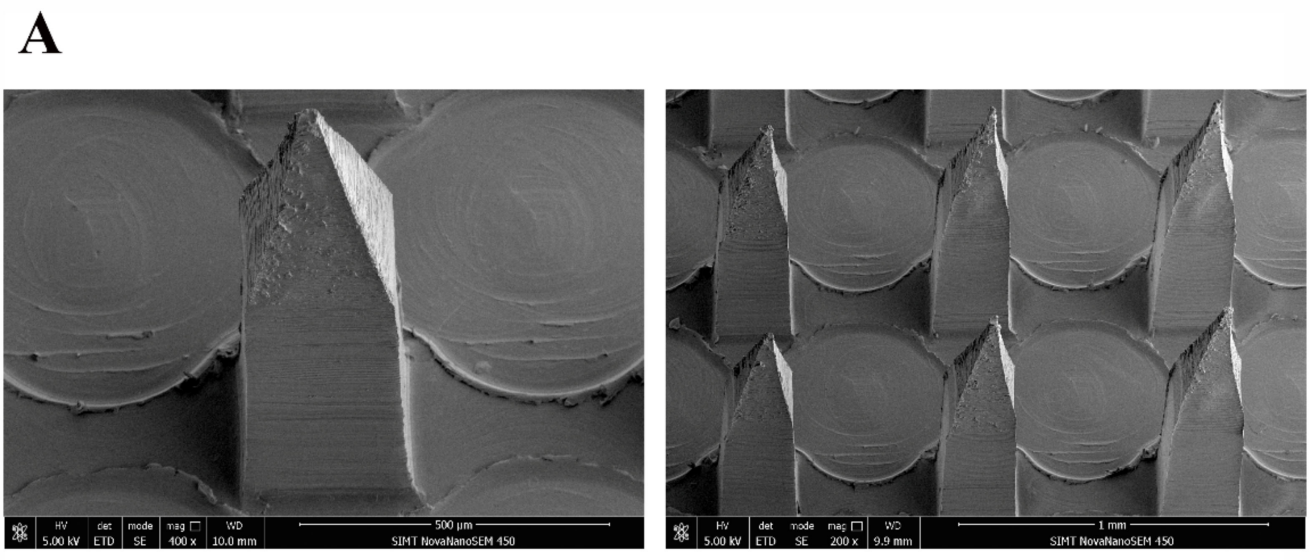

\section{B}
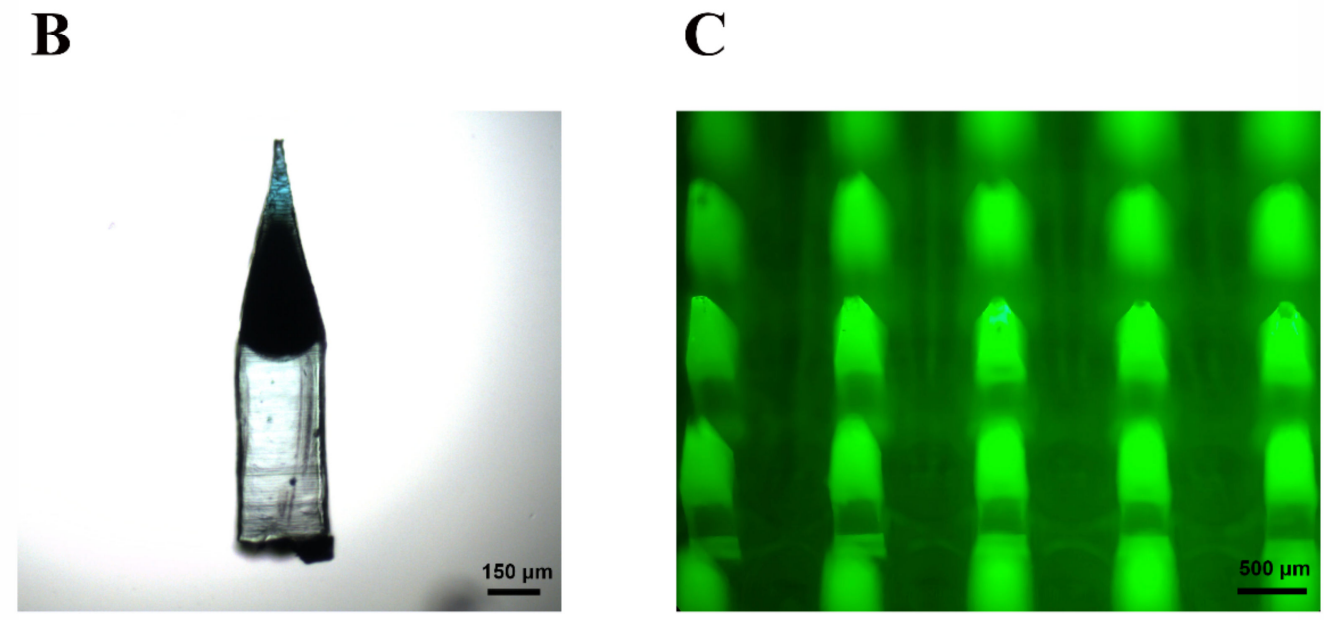

Figure 2. Characterization of the microneedles. (A) Scanning electron microscopy images show the morphology of the microneedles. (B) Drug distribution in the tip of the needle was illustrated by methylene blue. (C) Fluorescence images of the microneedles with FITC as a tracer reagent.

\subsection{The Mechanical Strength of the MNs}

The needles should be strong enough to puncture the skin [66,67]. In this experiment, the mechanical strength was tested by texture analyzer in vitro. The pressure force gradually increased with the increased displacement in the beginning and significantly increased when the displacement exceeded $0.2 \mathrm{~mm}$. The force dropped sharply at the displacement exceeding $0.80 \mathrm{~mm}$ (Figure 3A). We observed the morphology of the MNs when the force dropped sharply (Figure 3B), indicating broken tips. We assumed that the MNs broke at the point of sudden drop in pressure, which was defined as the failure force of MNs [67]. According to the previous study, MNs could be successfully inserted into skin without 
breaking when the failure force is greater than $0.24 \mathrm{~N} /$ needle $[68,69]$. The resultant failure force of dissolving MNs in this experiment could be quantified as $3 \mathrm{~N} /$ needle, proving that MNs provided enough strength to pierce skin.

A

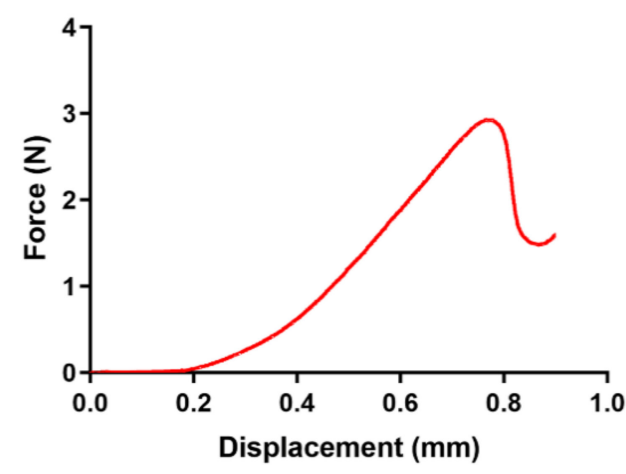

B

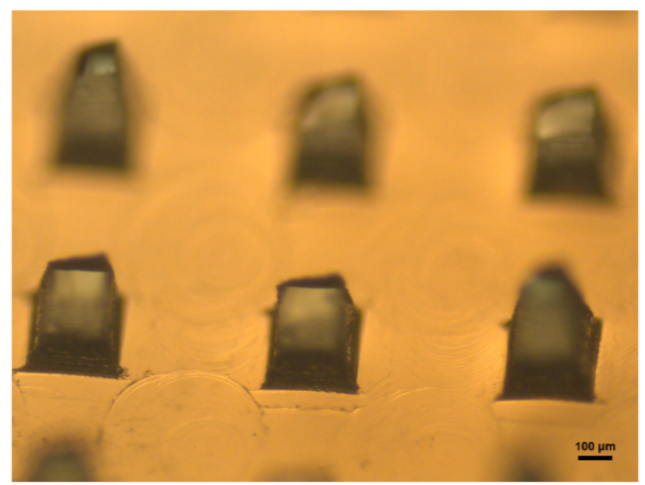

Figure 3. (A) The force-displacement curve of the microneedles. (B) The morphology of the microneedles treated by texture analyzer when the force dropped sharply.

\subsection{In Vitro Skin Insertion Tests}

To further evaluate the penetrating ability of MNs, dissolving MNs were applied into full thickness porcine skin for $5 \mathrm{~min}$ and then removed. As shown in Figure 4A, the micropores in the skin indicated that needles were inserted into the skin and dissolved successfully. The skin was further analyzed by H\&E staining. The results confirmed that the needles could pierce the SC and reach the dermis (Figure 4B). However, despite the length of $1200 \mu \mathrm{m}$, the needles only penetrated 200-300 $\mu \mathrm{m}$ of the skin, resulting from the existing wrinkling of the skin [70]. Since the drugs were loaded in the tips of the needles, the penetration depth was deep enough to release all of the cargo. In order to confirm this estimation, FITC was loaded in the tips of the MNs to mimic the drugs. Following the same procedure of administration, the skin was observed under the CLSM (Figure 4C). The FITC fluorescence was observed till the depth of $220 \mu \mathrm{m}$ beneath the skin surface, while the signals mainly resided from the depth of $50 \mu \mathrm{m}$ to $220 \mu \mathrm{m}$ and presented a narrowing trend. The results were in accordance with those from the tissue section. In addition, the FITC fluorescence was faint in the upper parts of the skin from the surface to the depth of $40 \mu \mathrm{m}$ due to the tip loading design. Therefore, it was confirmed that the needles could penetrate the SC and deliver all of the cargo into the skin.

\subsection{In Vivo Dissolution of the MNs after Insertion and the Recovery of the Skin}

The dissolution of the MNs in vivo was evaluated in abdominal skin of SD rats. For the convenience of observation, methylene blue was used to stain the MNs. The morphological changes of MNs after insertion into the skin for $5 \mathrm{~min}, 10 \mathrm{~min}$, and $20 \mathrm{~min}$ were recorded by using optical microscopy, respectively. At $5 \mathrm{~min}$ post administration, the blue of the needles was obviously lighter than that of the base, indicating the dissolution of the needle matrix; at 10 min post administration, the needles dissolved more than $50 \%$ and dissolved almost totally within $20 \mathrm{~min}$ (Figure 5). The results illustrate that the needles composed of HA and PVP-K90 could dissolve quickly after piercing. 
A

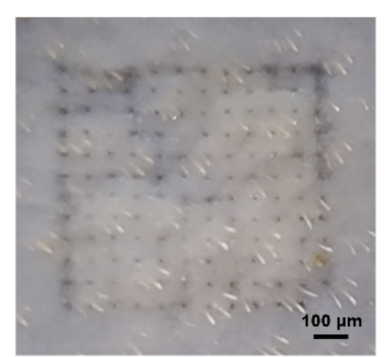

B

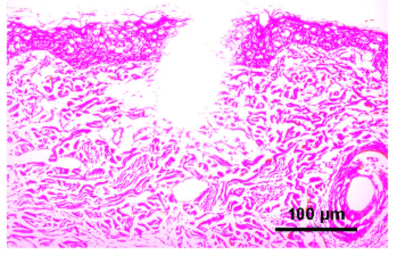

C

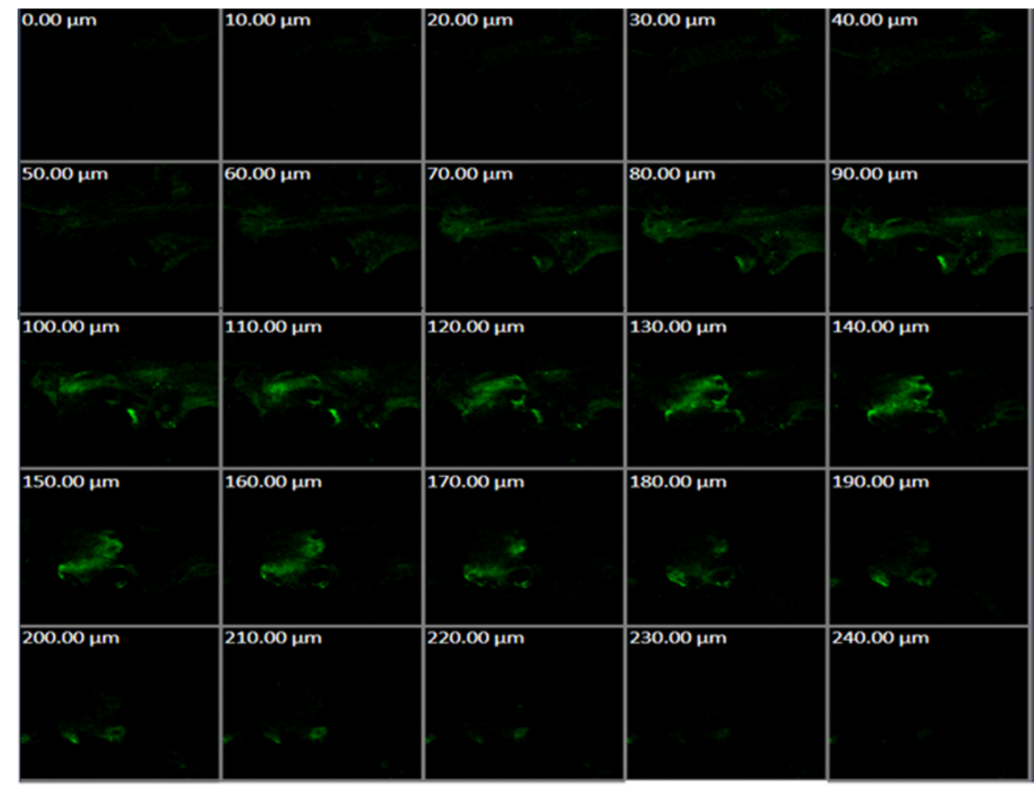

Figure 4. Skin insertion capability of the microneedles. (A) Digital camera image of porcine skin treated by microneedles. (B) H\&E staining of the skin treated by the microneedles. (C) CLSM photos of porcine skin treated by FITC-loaded microneedles.

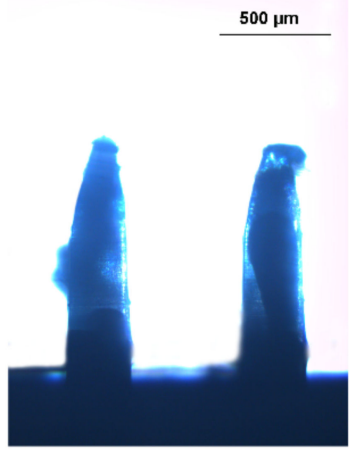

5 min

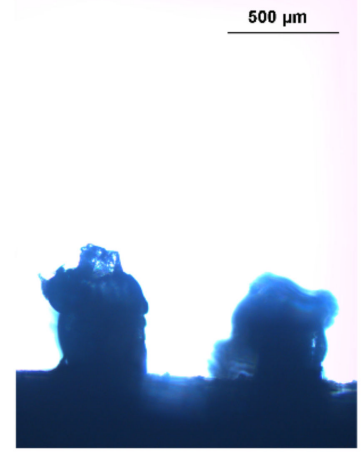

$10 \mathrm{~min}$

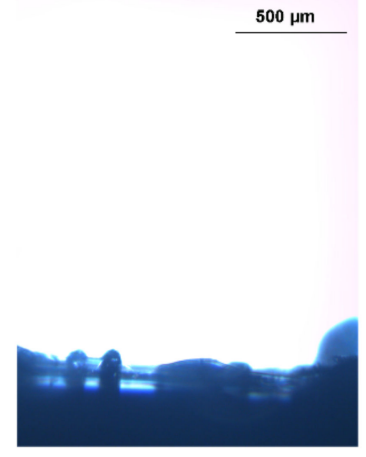

$20 \mathrm{~min}$

Figure 5. Morphological changes of the needles after insertion into the abdominal skin of SD rat at 5, 10 , and $20 \mathrm{~min}$.

\subsection{In Vivo Skin Recovery after MNs Insertion}

The recovery of the abdominal skin of the SD rat from the treatment of methylene blue loaded MNs was evaluated via observation with a digital camera (Figure 6). The MNs treatment did not induce obvious adverse effects except skin irritation and a trace of interstitial fluid exudate, which were recovered rapidly. The micropores created by MNs almost faded away at $3 \mathrm{~h}$ postinsertion. Only faint blue was left in the skin, and almost disappeared within $12 \mathrm{~h}$. 


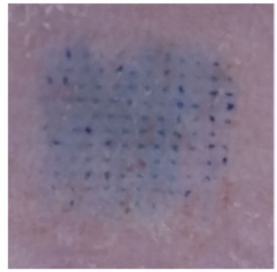

$\mathbf{O h}$

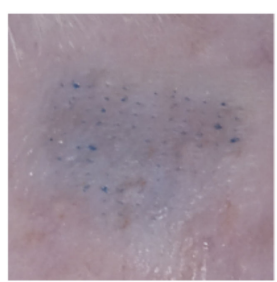

$3 \mathrm{~h}$

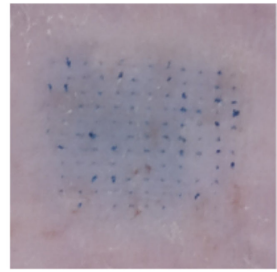

$1 \mathrm{~h}$

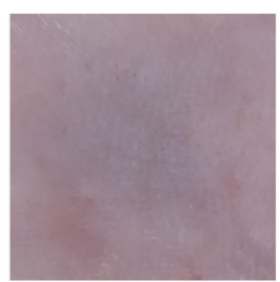

$6 \mathrm{~h}$

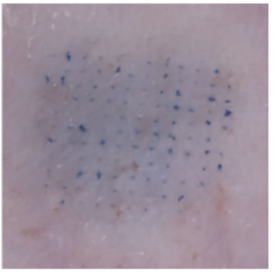

$\mathbf{2 h}$

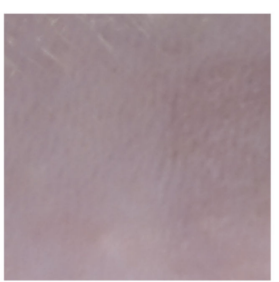

$12 \mathrm{~h}$

Figure 6. The recovery of abdominal skin in SD rat after treatment by the microneedles.

\subsection{Loading of Propranolol Hydrochloride in the MNs}

The previous results indicated that HA and PVP-K90 matrix provides excellent mechanical strength for skin penetration without compromising the dissolution. The two-step procedure of casting deposited the cargo in the tips and enabled delivery of all dose into the skin. Then we tried to load propranolol hydrochloride in the MNs using the same procedure, except that propranolol hydrochloride was dissolved in the tip solution. To investigate the loading capacity of the MNs, the concentration of propranolol hydrochloride in the tip solution was increased from $40 \mathrm{mg} / \mathrm{mL}$ to $80 \mathrm{mg} / \mathrm{mL}$ at equal intervals of $10 \mathrm{mg} / \mathrm{mL}$. The contents of propranolol hydrochloride in the corresponding microneedles were linearly increased from $781.90 \pm 51.85 \mu \mathrm{g}$ to $1718.65 \pm 34.92 \mu \mathrm{g}$ (Figure 7A). We didn't further increase the loading of propranolol hydrochloride because the content of $1500 \mu \mathrm{g}$ was adequate. Furthermore, the mechanical strength of the needles loading propranolol hydrochloride still maintained enough strength to puncture into skin, which was $1.7 \mathrm{~N} /$ needle at propranolol hydrochloride content of $1718.65 \pm 34.92 \mu \mathrm{g}$, as shown in Figure 7B.

\subsection{Drug Release from MNs}

In this experiment, drug release was conducted at $\mathrm{pH} 7.4$ under sink conditions. Owing to the excellent water solubility of HA and PVP-K90, there was an initial burst of drug release within $10 \mathrm{~min}$, in which the cumulative released percentage could be up to $90 \%$, as shown in Figure 8 . Afterward, the release rate gradually slowed down; approximately $100 \%$ amount of propranolol hydrochloride was released into the receiver medium at $20 \mathrm{~min}$, and the cumulative amount almost remained unchanged from $20 \mathrm{~min}$ to $1 \mathrm{~h}$. In addition, the cumulative propranolol hydrochloride release was almost equivalent to the drug content in MNs, which presumably means that the matrix materials had no interference in drug release from MNs. 


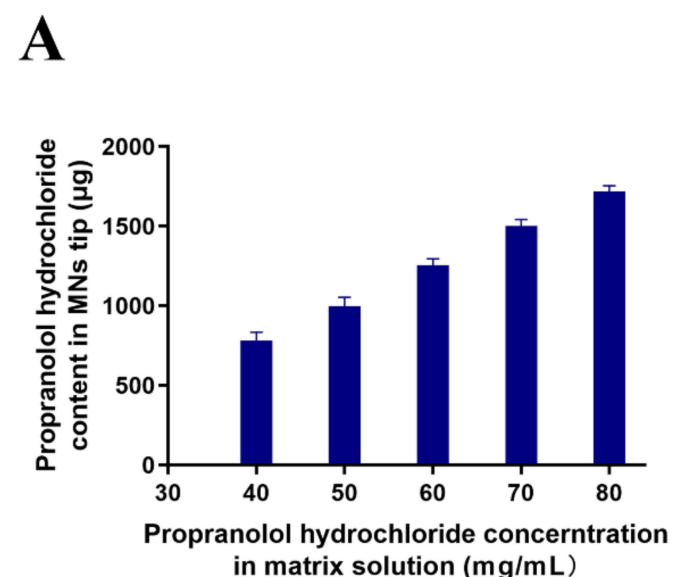

\section{B}

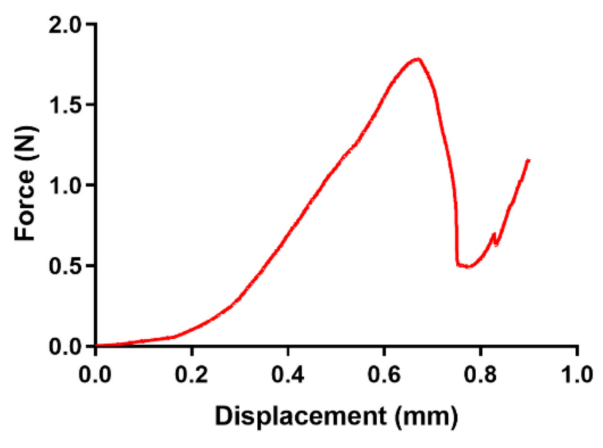

Figure 7. (A) Content of propranolol hydrochloride in the MNs was linearly increased with the increase of its content in the tip solution $(n=3)$. (B) The force-displacement curve of propranolol hydrochloride-loaded dissolving MNs patch.

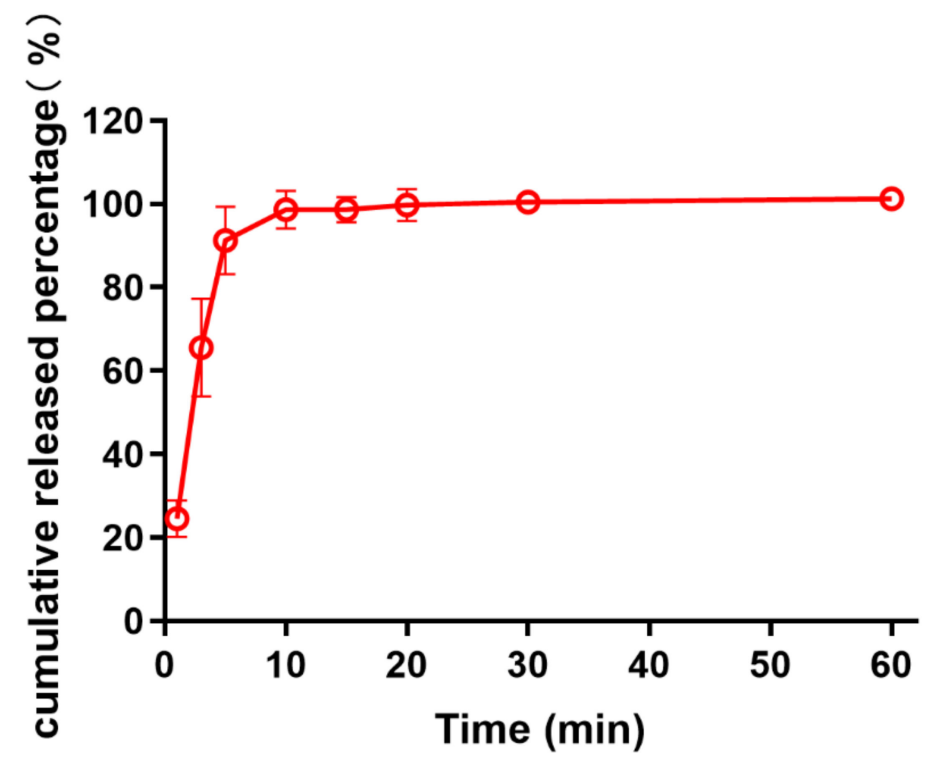

Figure 8. In vitro cumulative release percentage of propranolol hydrochloride from dissolving MNs $(n=3)$.

\subsection{In Vivo IVIS Image}

Furthermore, drug diffusion into skin after MNs application was determined by IVIS with rhodamine $B$ being a model drug because of its similar property to propranolol hydrochloride: a small molecule with good water solubility. Meanwhile, rhodamine B solution was hypodermic injected (HI) as a control. The IVIS images at different times are shown in Figure 9. It was found that fluorescence signals in abdominal skin of SD rats were intense after MNs treatment and were sustained for $12 \mathrm{~h}$. In contrast, fluorescence signals disappeared quickly in the HI group. The results demonstrated that MNs formed by HA and PVP-K90 could quickly dissolve via absorbing the interstitial fluid, and drugs were then gradually diffused into the skin from the dissolved matrix. Thus, the skin area with a high local drug concentration became a drug depot to further release the drug continuously for nearly $12 \mathrm{~h}$. The prolonged drug retention may be associated with the material used in the dissolving $\mathrm{MNs}^{\prime}$ fabrication. It was previously reported that hydration of the epidermis induced by HA could be beneficial for drug skin retention and slow permeation [59,71]. 


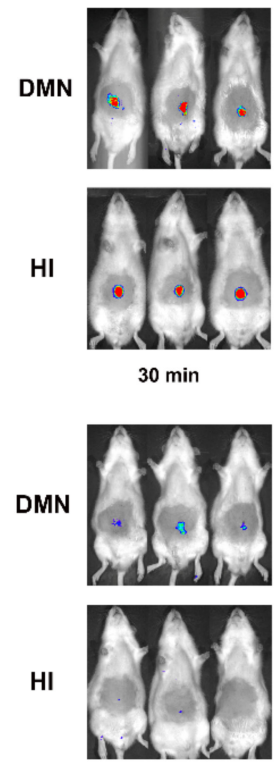

$8 \mathrm{~h}$
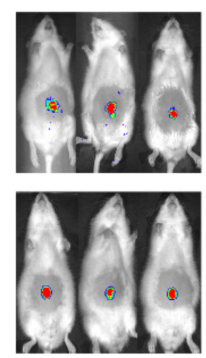

$1 \mathrm{~h}$
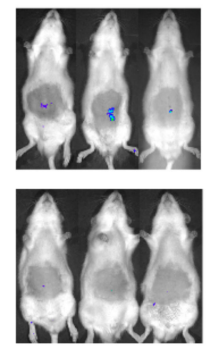

$10 \mathrm{~h}$
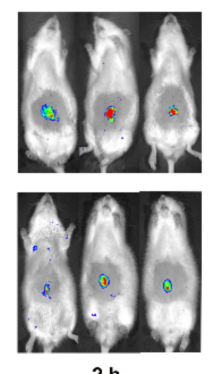

$2 \mathrm{~h}$
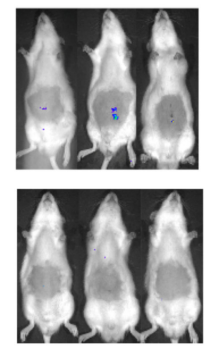

$12 \mathrm{~h}$
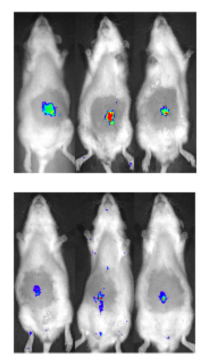

$4 \mathrm{~h}$
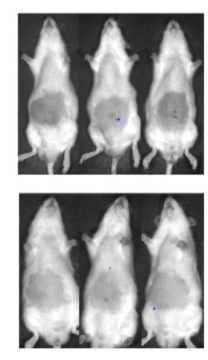

$24 \mathrm{~h}$

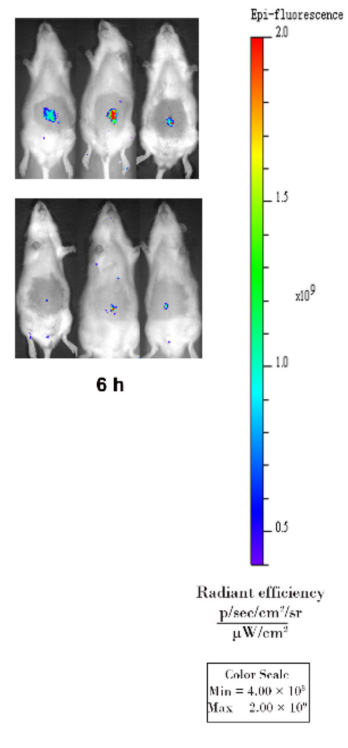

Figure 9. In vivo fluorescence intensity images of SD rats after application of rhodamine B via dissolving MNs or hypodermic injected $(n=3)$.

\subsection{Permeation and Skin Retention}

Many previous studies have confirmed that dissolving MNs could be utilized as an efficient tool for improving the penetration rate and delivery efficiency of an encapsulated drug $[35,72,73]$. In this experiment, full thickness isolated porcine skin was used as a drug permeable membrane. The permeation profiles of propranolol hydrochloride from different approaches are shown in Figure 10. The solution that was applied to the intact skin showed inferior permeability to the other two groups due to the hydrophilicity of propranolol hydrochloride. The permeated amounts of propranolol hydrochloride in this group were the lowest among all groups at all time points. Pretreatment with solid MNs created micropores in the skin, facilitating diffusion of propranolol hydrochloride from outside the skin into the skin. Therefore, the aqueous solution applied to the pretreated skin displayed accelerated penetration, which is shown by the continuously increasing slope of the curve (Figure 10A). However, although pretreatment with solid MNs could create micropores in the skin for diffusion of propranolol hydrochloride, the lipids that reside among the coenocytes may still delay the diffusion of hydrophilic molecules such as propranolol hydrochloride $[74,75]$. By contrast, the dissolving MNs directly delivered propranolol hydrochloride into the skin, while the needle matrix dissolved rapidly. The absence of the diffusion step from outside the skin into the skin endowed even faster permeation of propranolol hydrochloride from the dissolving MNs than the solution that was applied to the pretreated skin. Thus, compared with the solution counterpart, irrespective of being applied to intact or pretreated skin, the dissolving MNs showed significantly higher permeating amounts of propranolol hydrochloride at all time points.

Furthermore, the skin retention of propranolol hydrochloride was also evaluated. It is necessary to establish a method for determining the drug content in the skin for comparison, which will be mandatory for the optimization of transdermal medicinal formulations. Skin concentrations of propranolol hydrochloride at different times were tested and are shown in Figure 10B. The result demonstrates that skin concentrations in the dissolving MNs group were higher than those in the MN-pretreated group or control group, and propranolol hydrochloride could be detected in the skin within $12 \mathrm{~h}$. After MNs insertion, HA and PVP-K90 dissolved by absorbing interstitial fluid to form a high local drug concentration at the beginning and then released drug continuously. Therefore, dissolving MNs may 
contribute to improved administration regimens by increasing the concentration of the drug in the local skin and decreasing dosing frequency.
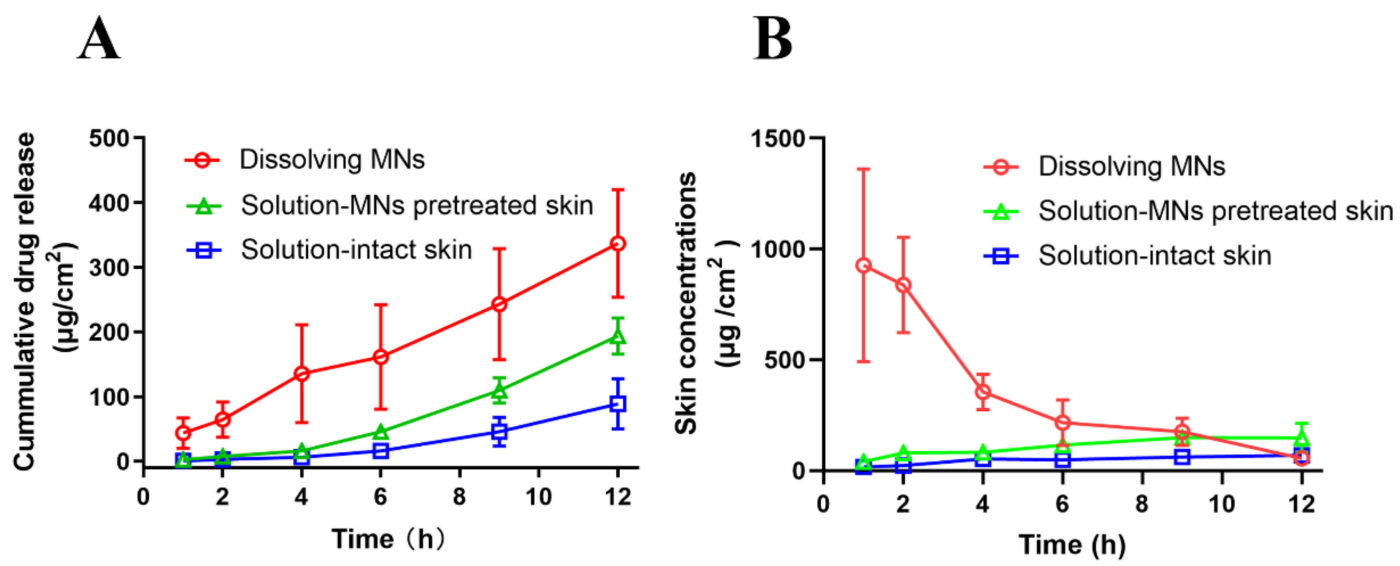

Figure 10. (A) Permeation profiles of propranolol hydrochloride into a receiver fluid after application of propranolol hydrochloride in different approaches to full thickness excised porcine skin $(n=5)$. (B) Skin concentration of propranolol hydrochloride after application of propranolol hydrochloride in different approaches to full thick excised porcine skin $(n=3)$. The amount of drug was $1.5 \mathrm{mg}$.

\section{Conclusions}

Oral propranolol for the treatment of IHs may have potential adverse effects due to systemic absorption. Dermal administration of propranolol could increase the local concentration of the drug, reduce the frequency of administration, and improve patient compliance. Propranolol hydrochloride loaded microneedles were fabricated in this study. The matrix composed of HA and PVP-K90 provided excellent mechanical strength for piercing the skin and dissolved quickly when absorbing interstitial fluid after insertion. Propranolol hydrochloride was primarily concentrated in the tip via a two-step procedure. Most important, the cumulative permeation and skin retention of propranolol hydrochloride in dissolving MNs treated skin were much higher than those of propranolol hydrochloride solution applied in blank skin and solid MNs treated skin. Furthermore, the benefit of increasing drug skin retention induced by HA-mediated skin hydration is that the skin can act as a drug repository, allowing continuous release of the drug. Taken together, dissolving MNs made from HA and PVP-K90 display great advantages for transdermal delivery. Nevertheless, further animal experiments are necessary to evaluate the pharmacokinetic and pharmacodynamic profiles of the MNs for successful application.

Author Contributions: J.H., Y.L., and W.W. contributed to the concept and design of the experiment. J.H., Z.Z., X.Z., and L.L. performed the experiment and analyzed the data. J.H. wrote the original draft. J.H., Y.L., W.W., and J.Q. reviewed and revised the article. All authors contributed to the final manuscript. All authors have read and agreed to the published version of the manuscript.

Funding: This research received no external funding.

Institutional Review Board Statement: The study was conducted according to the guidelines of the Declaration of Helsinki, and approved by the Institutional Animal Care and Use Committee at School of Pharmacy, Fudan University (protocol code 2019-03-YJ-LY-01 and date of approval March 7, 2019).

Informed Consent Statement: Not applicable.

Data Availability Statement: Not applicable.

Acknowledgments: The authors would like to thank Wu, C.B. from the College of Pharmacy, Jinan University, for providing PDMS negative mold.

Conflicts of Interest: The authors declare that there are no conflicts of interest. 


\section{References}

1. Aqil, M.; Sultana, Y.; Ali, A. Transdermal delivery of beta-blockers. Expert Opin. Drug Deliv. 2006, 3, 405-418. [CrossRef] [PubMed]

2. Dharadhar, S.; Majumdar, A.; Dhoble, S.; Patravale, V. Microneedles for transdermal drug delivery: A systematic review. Drug Dev. Ind. Pharm. 2019, 45, 188-201. [CrossRef] [PubMed]

3. Alany, R. Topical and transdermal formulation and drug delivery. Pharm. Dev. Technol. 2017, 22, 457. [CrossRef] [PubMed]

4. Prausnitz, M.R.; Langer, R. Transdermal drug delivery. Nat. Biotechnol. 2008, 26, 1261-1268. [CrossRef]

5. Waghule, T.; Singhvi, G.; Dubey, S.K.; Pandey, M.M.; Gupta, G.; Singh, M.; Dua, K. Microneedles: A smart approach and increasing potential for transdermal drug delivery system. Biomed. Pharmacother. 2019, 109, 1249-1258. [CrossRef]

6. Leone, M.; Mönkäre, J.; Bouwstra, J.A.; Kersten, G. Dissolving microneedle patches for dermal vaccination. Pharm. Res. 2017, 34, 2223-2240. [CrossRef]

7. Hao, Y.; Li, W.; Zhou, X.; Yang, F.; Qian, Z. Microneedles-based transdermal drug delivery systems: A review. J. Biomed. Nanotechnol. 2017, 13, 1581-1597. [CrossRef]

8. Pikal, M.J. The role of electroosmotic flow in transdermal iontophoresis. Adv. Drug Deliv. Rev. 2001, 46, 281-305. [CrossRef]

9. Zuo, J.; Du, L.; Li, M.; Liu, B.; Zhu, W.; Jin, Y. Transdermal enhancement effect and mechanism of iontophoresis for non-steroidal anti-inflammatory drugs. Int. J. Pharm. 2014, 466, 76-82. [CrossRef]

10. Kanikkannan, N. Iontophoresis-based transdermal delivery systems. BioDrugs 2002, 16, 339-347. [CrossRef]

11. Oberli, M.A.; Schoellhammer, C.M.; Langer, R.; Blankschtein, D. Ultrasound-enhanced transdermal delivery: Recent advances and future challenges. Ther. Deliv. 2014, 5, 843-857. [CrossRef]

12. Seah, B.C.; Teo, B.M. Recent advances in ultrasound-based transdermal drug delivery. Int. J. Nanomed. 2018, 13, 7749-7763. [CrossRef]

13. Park, D.; Park, H.; Seo, J.; Lee, S. Sonophoresis in transdermal drug deliverys. Ultrasonics 2014, 54, 56-65. [CrossRef]

14. Murthy, S.N.; Sammeta, S.M.; Bowers, C. Magnetophoresis for enhancing transdermal drug delivery: Mechanistic studies and patch design. J. Control. Release 2010, 148, 197-203. [CrossRef]

15. Sammeta, S.M.; Repka, M.A.; Murthy, S.N. Magnetophoresis in combination with chemical enhancers for transdermal drug delivery. Drug Dev. Ind. Pharm. 2011, 37, 1076-1082. [CrossRef]

16. Akhtar, N.; Singh, V.; Yusuf, M.; Khan, R.A. Non-invasive drug delivery technology: Development and current status of transdermal drug delivery devices, techniques and biomedical applications. Biomed. Tech. 2020, 65, 243-272. [CrossRef]

17. Yang, G.; Zhang, Y.; Gu, Z. Punching and electroporation for enhanced transdermal drug delivery. Theranostics 2018, 8, 3688-3690. [CrossRef]

18. Huang, D.; Huang, Y.; Li, Z. Transdermal delivery of nucleic acid mediated by punching and electroporation. Methods Mol. Biol. 2020, 2050, 101-112.

19. Chen, X.; Zhu, L.; Li, R.; Pang, L.; Zhu, S.; Ma, J.; Du, L.; Jin, Y. Electroporation-enhanced transdermal drug delivery: Effects of $\log$, pk(a), solubility and penetration time. Eur. J. Pharm. Sci. 2020, 151, 105410. [CrossRef]

20. Wong, T.W. Electrical, magnetic, photomechanical and cavitational waves to overcome skin barrier for transdermal drug delivery. J. Control. Release 2014, 193, 257-269. [CrossRef]

21. Lee, S.; McAuliffe, D.J.; Kollias, N.; Flotte, T.J.; Doukas, A.G. Permeabilization and recovery of the stratum corneum in vivo: The synergy of photomechanical waves and sodium lauryl sulfate. Lasers Surg. Med. 2001, 29, 145-150. [CrossRef]

22. Lee, S.; Kollias, N.; McAuliffe, D.J.; Flotte, T.J.; Doukas, A.G. Topical drug delivery in humans with a single photomechanical wave. Pharm. Res. 1999, 16, 1717-1721. [CrossRef]

23. Chen, Z.; Lv, Y.; Qi, J.; Zhu, Q.; Lu, Y.; Wu, W. Overcoming or circumventing the stratum corneum barrier for efficient transcutaneous immunization. Drug Discov. Today 2018, 23, 181-186. [CrossRef]

24. Pireddu, R.; Schlich, M.; Marceddu, S.; Valenti, D.; Pini, E.; Fadda, A.M.; Lai, F.; Sinico, C. Nanosuspensions and microneedles roller as a combined approach to enhance diclofenac topical bioavailability. Pharmaceutics 2020, 12, 1140. [CrossRef]

25. Ramaut, L.; Hoeksema, H.; Pirayesh, A.; Stillaert, F.; Monstrey, S. Microneedling: Where do we stand now? A systematic review of the literature. J. Plast. Reconstr. Aesthet. Surg. 2018, 71, 1-14. [CrossRef] [PubMed]

26. Kapoor, Y.; Milewski, M.; Dick, L.; Zhang, J.; Bothe, J.R.; Gehrt, M.; Manser, K.; Nissley, B.; Petrescu, I.; Johnson, P.; et al. Coated microneedles for transdermal delivery of a potent pharmaceutical peptide. Biomed. Microdevices 2019, 22, 7. [CrossRef]

27. Chen, Z.; He, J.; Qi, J.; Zhu, Q.; Wu, W.; Lu, Y. Long-acting microneedles: A progress report of the state-of-the-art techniques. Drug Discov. Today 2020, 25, 1462-1468. [CrossRef]

28. Ita, K. Dissolving microneedles for transdermal drug delivery: Advances and challenges. Biomed. Pharmacother. 2017, 93, 1116-1127. [CrossRef]

29. Li, J.; Zeng, M.; Shan, H.; Tong, C. Microneedle patches as drug and vaccine delivery platform. Curr. Med. Chem. 2017, 24, 2413-2422. [CrossRef] [PubMed]

30. Ahmed Saeed Al-Japairai, K.; Mahmood, S.; Hamed Almurisi, S.; Reddy Venugopal, J.; Rebhi Hilles, A.; Azmana, M.; Raman, S. Current trends in polymer microneedle for transdermal drug delivery. Int. J. Pharm. 2020, 587, 119673. [CrossRef]

31. Maurya, A.; Nanjappa, S.H.; Honnavar, S.; Salwa, M.; Murthy, S.N. Rapidly dissolving microneedle patches for transdermal iron replenishment therapy. J. Pharm. Sci. 2018, 107, 1642-1647. [CrossRef] [PubMed]

32. Pei, P.; Yang, F.; Liu, J.; Hu, H.; Du, X.; Hanagata, N.; Zhao, S.; Zhu, Y. Composite-dissolving microneedle patches for chemotherapy and photothermal therapy in superficial tumor treatment. Biomater. Sci. 2018, 6, 1414-1423. [CrossRef] [PubMed] 
33. Cole, G.; McCaffrey, J.; Ali, A.A.; McBride, J.W.; McCrudden, C.M.; Vincente-Perez, E.M.; Donnelly, R.F.; McCarthy, H.O. Dissolving microneedles for DNA vaccination: Improving functionality via polymer characterization and rala complexation. Hum. Vaccin. Immunother. 2017, 13, 50-62. [CrossRef] [PubMed]

34. Wang, W.; Liu, H.M.; Zhou, J.; Wang, Y.G.; Feng, X.; Tang, H.; Yan, Q.; Zhu, R.S.; Wu, Y.W.; Wang, X.G.; et al. Skin test of tuberculin purified protein derivatives with a dissolving microneedle-array patch. Drug Deliv. Transl. Res. 2019, 9, 795-801. [CrossRef]

35. Yang, H.; Kang, G.; Jang, M.; Um, D.J.; Shin, J.; Kim, H.; Hong, J.; Jung, H.; Ahn, H.; Gong, S.; et al. Development of lidocaine-loaded dissolving microneedle for rapid and efficient local anesthesia. Pharmaceutics 2020, 12, 1067. [CrossRef]

36. Fu, D.G. Cardiac arrhythmias: Diagnosis, symptoms, and treatments. Cell Biochem. Biophys. 2015, 73, 291-296. [CrossRef]

37. Léauté-Labrèze, C.; Dumas de la Roque, E.; Hubiche, T.; Boralevi, F.; Thambo, J.B.; Taïeb, A. Propranolol for severe hemangiomas of infancy. N. Engl. J. Med. 2008, 358, 2649-2651. [CrossRef]

38. Leaute-Labreze, C.; Harper, J.I.; Hoeger, P.H. Infantile haemangioma. Lancet 2017, 390, 85-94. [CrossRef]

39. Wedgeworth, E.; Glover, M.; Irvine, A.D.; Neri, I.; Baselga, E.; Clayton, T.H.; Beattie, P.E.; Bjerre, J.V.; Burrows, N.P.; Foelster-Holst, R.; et al. Propranolol in the treatment of infantile haemangiomas: Lessons from the european propranolol in the treatment of complicated haemangiomas (pitch) taskforce survey. Br. J. Dermatol. 2016, 174, 594-601. [CrossRef]

40. Al-Haddad, C.; El Salloukh, N.A.; El Moussawi, Z. B-blockers in the treatment of periocular infantile hemangioma. Curr. Opin. Ophthalmol. 2019, 30, 319-325. [CrossRef]

41. Marey, H.M.; Elmazar, H.F.; Mandour, S.S.; Khairy, H.A. Combined oral and topical beta blockers for the treatment of early proliferative superficial periocular infantile capillary hemangioma. J. Pediatr. Ophthalmol. Strabismus. 2018, 55, 37-42. [CrossRef]

42. Zaher, H.; Rasheed, H.; Esmat, S.; Hegazy, R.A.; Gawdat, H.I.; Hegazy, R.A.; El-Komy, M.; Abdelhalim, D.M. Propranolol and infantile hemangiomas: Different routes of administration, a randomized clinical trial. Eur. J. Dermatol. 2013, 23, 646-652. [CrossRef]

43. Al-Majed, A.A.; Bakheit, A.H.H.; Abdel Aziz, H.A.; Alajmi, F.M.; AlRabiah, H. Propranolol. Profiles Drug Subst. Excip. Relat. Methodol. 2017, 42, 287-338.

44. Kovačević, M.; Lukinović Škudar, V.; Maričić, G.; Krnjević-Pezić, G.; Stanimirović, A. Topical propranolol cream in treatment of superficial infantile hemangiomas: A literature review and 4 years of clinical experience. Acta Derm. Alp. Pannonica Adriat. 2014, 23, 75-78. [CrossRef]

45. Price, A.; Rai, S.; McLeod, R.W.J.; Birchall, J.C.; Elhassan, H.A. Topical propranolol for infantile haemangiomas: A systematic review. J. Eur. Acad. Dermatol Venereol. 2018, 32, 2083-2089. [CrossRef]

46. Da Silva Marques, Z.T.; Santos-Oliveira, R.; de Oliveira de Siqueira, L.B.; Cardoso, V.D.S.; de Freitas, Z.M.F.; Barros, R.; Villa, A.L.V.; Monteiro, M.; Dos Santos, E.P.; Ricci-Junior, E. Development and characterization of a nanoemulsion containing propranolol for topical delivery. Int. J. Nanomed. 2018, 13, 2827-2837. [CrossRef]

47. Pamornpathomkul, B.; Ngawhirunpat, T.; Tekko, I.A.; Vora, L.; McCarthy, H.O.; Donnelly, R.F. Dissolving polymeric microneedle arrays for enhanced site-specific acyclovir delivery. Eur. J. Pharm. Sci. 2018, 121, 200-209. [CrossRef]

48. An, M.; Liu, H. Dissolving microneedle arrays for transdermal delivery of amphiphilic vaccines. Small 2017, 13, 1700164. [CrossRef]

49. Dillon, C.; Hughes, H.; O’Reilly, N.J.; Allender, C.J.; Barrow, D.A.; McLoughlin, P. Dissolving microneedle based transdermal delivery of therapeutic peptide analogues. Int. J. Pharm. 2019, 565, 9-19. [CrossRef]

50. Kang, G.; Tu, T.N.T.; Kim, S.; Yang, H.; Jang, M.; Jo, D.; Ryu, J.; Baek, J.; Jung, H. Adenosine-loaded dissolving microneedle patches to improve skin wrinkles, dermal density, elasticity and hydration. Int. J. Cosmet. Sci. 2018, 40, 199-206. [CrossRef]

51. Bok, M.; Zhao, Z.J.; Hwang, S.H.; Kang, H.J.; Jeon, S.; Ko, J.; Jeong, J.; Song, Y.S.; Lim, E.; Jeong, J.H. Effective dispensing methods for loading drugs only to the tip of DNA microneedles. Pharmaceutics 2020, 12, 954. [CrossRef] [PubMed]

52. Tarbox, T.N.; Watts, A.B.; Cui, Z.; Williams, R.O., 3rd. An update on coating/manufacturing techniques of microneedles. Drug Deliv. Transl. Res. 2018, 8, 1828-1843. [CrossRef] [PubMed]

53. Gittard, S.D.; Ovsianikov, A.; Monteiro-Riviere, N.A.; Lusk, J.; Morel, P.; Minghetti, P.; Lenardi, C.; Chichkov, B.N.; Narayan, R.J. Fabrication of polymer microneedles using a two-photon polymerization and micromolding process. J. Diabetes Sci. Technol. 2009, 3, 304-311. [CrossRef] [PubMed]

54. Arshad, M.S.; Zafar, S.; Zahra, A.T.; Zaman, M.H.; Akhtar, A.; Kucuk, I.; Farhan, M.; Chang, M.W.; Ahmad, Z. Fabrication and characterisation of self-applicating heparin sodium microneedle patches. J. Drug Target. 2021, 29, 60-68. [CrossRef]

55. Bhatnagar, S.; Bankar, N.G.; Kulkarni, M.V.; Venuganti, V.V.K. Dissolvable microneedle patch containing doxorubicin and docetaxel is effective in 4t1 xenografted breast cancer mouse model. Int. J. Pharm. 2019, 556, 263-275. [CrossRef]

56. Sadeqi, A.; Nejad, H.R.; Kiaee, G.; Sonkusale, S. Cost-effective fabrication of chitosan microneedles for transdermal drug delivery. In Proceedings of the 2018 40th Annual International Conference of the IEEE Engineering in Medicine and Biology Society (EMBC), Honolulu, HI, USA, 17-21 July 2018; pp. 5737-5740.

57. Chen, Y.W.; Chen, M.C.; Wu, K.W.; Tu, T.Y. A facile approach for rapid prototyping of microneedle molds, microwells and micro-through-holes in various substrate materials using co (2) laser drilling. Biomedicines 2020, 8, 427. [CrossRef]

58. How, K.N.; Yap, W.H.; Lim, C.L.H.; Goh, B.H.; Lai, Z.W. Hyaluronic acid-mediated drug delivery system targeting for inflammatory skin diseases: A mini review. Front. Pharmacol. 2020, 11, 1105. [CrossRef]

59. Du, H.; Liu, P.; Zhu, J.; Lan, J.; Li, Y.; Zhang, L.; Zhu, J.; Tao, J. Hyaluronic acid-based dissolving microneedle patch loaded with methotrexate for improved treatment of psoriasis. ACS Appl. Mater. Interfaces 2019, 11, 43588-43598. [CrossRef] 
60. Choi, S.Y.; Kwon, H.J.; Ahn, G.R.; Ko, E.J.; Yoo, K.H.; Kim, B.J.; Lee, C.; Kim, D. Hyaluronic acid microneedle patch for the improvement of crow's feet wrinkles. Dermatol. Ther. 2017, 30, e12546. [CrossRef]

61. Swathi, H.P.; Anusha Matadh, V.; Paul Guin, J.; Narasimha Murthy, S.; Kanni, P.; Varshney, L.; Suresh, S.; Shivakumar, H.N. Effect of gamma sterilization on the properties of microneedle array transdermal patch system. Drug Dev. Ind. Pharm. 2020, 46, 606-620. [CrossRef]

62. Aung, N.N.; Ngawhirunpat, T.; Rojanarata, T.; Patrojanasophon, P.; Opanasopit, P.; Pamornpathomkul, B. Hpmc/pvp dissolving microneedles: A promising delivery platform to promote trans-epidermal delivery of alpha-arbutin for skin lightening. AAPS PharmSciTech 2019, 21, 25. [CrossRef]

63. Balmert, S.C.; Carey, C.D.; Falo, G.D.; Sethi, S.K.; Erdos, G.; Korkmaz, E.; Falo, L.D., Jr. Dissolving undercut microneedle arrays for multicomponent cutaneous vaccination. J. Control. Release 2020, 317, 336-346. [CrossRef]

64. Lee, I.C.; Lin, W.M.; Shu, J.C.; Tsai, S.W.; Chen, C.H.; Tsai, M.T. Formulation of two-layer dissolving polymeric microneedle patches for insulin transdermal delivery in diabetic mice. J Biomed. Mater. Res. A 2017, 105, 84-93. [CrossRef]

65. Yao, W.; Tao, C.; Zou, J.; Zheng, H.; Zhu, J.; Zhu, Z.; Zhu, J.; Liu, L.; Li, F.; Song, X. Flexible two-layer dissolving and safing microneedle transdermal of neurotoxin: A biocomfortable attempt to treat rheumatoid arthritis. Int. J. Pharm. 2019, 563, 91-100. [CrossRef]

66. Ahmad, Z.; Khan, M.I.; Siddique, M.I.; Sarwar, H.S.; Shahnaz, G.; Hussain, S.Z.; Bukhari, N.I.; Hussain, I.; Sohail, M.F. Fabrication and characterization of thiolated chitosan microneedle patch for transdermal delivery of tacrolimus. AAPS PharmSciTech 2020, 21, 68. [CrossRef]

67. Wang, C.; Ye, Y.; Hochu, G.M.; Sadeghifar, H.; Gu, Z. Enhanced cancer immunotherapy by microneedle patch-assisted delivery of anti-pd1 antibody. Nano Lett. 2016, 16, 2334-2340. [CrossRef]

68. Gittard, S.D.; Chen, B.; Xu, H.; Ovsianikov, A.; Chichkov, B.N.; Monteiro-Riviere, N.A.; Narayan, R.J. The effects of geometry on skin penetration and failure of polymer microneedles. J. Adhes. Sci. Technol. 2013, 27, 227-243. [CrossRef]

69. Ita, K. Reflections on the insertion and fracture forces of microneedles. Curr. Drug Deliv. 2017, 14, 357-363. [CrossRef]

70. Lee, J.W.; Park, J.H.; Prausnitz, M.R. Dissolving microneedles for transdermal drug delivery. Biomaterials 2008, 29, 2113-2124. [CrossRef]

71. Brown, M.B.; Jones, S.A. Hyaluronic acid: A unique topical vehicle for the localized delivery of drugs to the skin. J. Eur. Acad. Dermatol. Venereol. 2005, 19, 308-318. [CrossRef]

72. Lee, S.; Lahiji, S.F.; Jang, J.; Jang, M.; Jung, H. Micro-pillar integrated dissolving microneedles for enhanced transdermal drug delivery. Pharmaceutics 2019, 11, 402. [CrossRef]

73. Lee, B.M.; Lee, C.; Lahiji, S.F.; Jung, U.W.; Chung, G.; Jung, H. Dissolving microneedles for rapid and painless local anesthesia. Pharmaceutics 2020, 12, 366. [CrossRef]

74. Dong, P.; Teutloff, C.; Lademann, J.; Patzelt, A.; Schäfer-Korting, M.; Meinke, M.C. Solvent effects on skin penetration and spatial distribution of the hydrophilic nitroxide spin probe pca investigated by epr. Cell Biochem. Biophys. 2020, 78, 127-137. [CrossRef]

75. Das, C.; Olmsted, P.D. The physics of stratum corneum lipid membranes. Philos. Trans. R. Soc. A: Math. Phys. Eng. Sci. 2016, 374, 20150126. [CrossRef] 